\title{
COMPENSAÇÕES FINANCEIRAS E ROYALTIES HIDRELÉTRICOS NA DETERMINAÇÃO DO INVESTIMENTO PÚBLICO E DAS DESPESAS SOCIAIS ${ }^{1}$
}

\author{
Mirelle Cristina de Abreu Quintela ${ }^{2}$ \\ Fátima Marília Andrade de Carvalho ${ }^{3}$
}

Resumo: O objetivo deste trabalho é avaliar o efeito do recurso financeiro "extra" compensações financeiras e royalties hidrelétricos - na formação da receita orçamentária e na determinação dos gastos públicos dos municípios recebedores em Minas Gerais. Partiu-se das discussões sobre os determinantes da expansão dos gastos governamentais e das contas públicas municipais. Estimaram-se regressões com dados em painel, para cada um dos gastos municipais considerados (investimento, habitação e urbanismo, saúde e saneamento e educação e cultura), e calcularam-se índices de proporções e taxas de crescimento de gastos e receitas. Em cada função estimada, as principais fontes de receita municipal (recursos compensatórios, Fundo de Participação Municipal - FPM, Imposto Sobre Circulação de Mercadorias e Serviços - ICMS, Imposto Predial Territorial Urbano - IPTU, Imposto Sobre Serviço de Qualquer Natureza - ISS e taxas municipais) foram consideradas como variáveis explicativas. Os resultados mostraram que a disponibilidade de receita orçamentária foi significativa para determinação dos gastos públicos municipais, e, para os municípios mineiros beneficiados com recursos compensatórios hidrelétricos, em especial, foi confirmado o grande poder explicativo das compensações financeiras e dos royalties hidrelétricos sobre a expansão do gasto municipal em infraestrutura local. Isso foi captado, principalmente, pelas elasticidades das funções estimadas para investimento, despesas com habitação e urbanismo e com saúde e saneamento.

Palavras-chave: Royalties hidrelétricos, receita orçamentária, gastos públicos.

\footnotetext{
Recebido em: 09/12/09; Aceito em: 30/03/10.

Doutoranda em Economia Aplicada pela UFV e Professora da UFVJM. E-mail: mirelle.quintela@ufvjm.edu.br Professora do Centro Universitário UNA e Bolsista da Secretaria de Estado de Ciência, Tecnologia e Ensino Superior de Minas Gerais. E-mail: fatima.carvalho@tecnologia.mg.gov.br
} 


\section{Introdução}

A compensação financeira hidrelétrica, ou os royalties hidrelétricos, corresponde à indenização paga aos Estados, ao Distrito Federal, aos Municípios e aos Órgãos da Administração Direta da União pela exploração do recurso hídrico e pela ocupação do espaço físico.

Esse recurso financeiro compensatório passa a representar parcela significativa da receita orçamentária dos municípios por ele beneficiados e, por ser vedada a sua aplicação em pagamento de dívida e em quadro permanente de pessoal (art. $8^{\circ}$ da Lei no 7.990/1989), sua utilização é destinada ao financiamento de investimentos e de melhorias locais (ANEEL, 2007a).

Com base nas informações da ANEEL (2007c), os recursos compensatórios hidrelétricos são indenizações devidas por empresas e concessionárias autorizadas a produzir energia elétrica, como forma de pagamento pelo uso do recurso hídrico e pelo alagamento provocado pela construção dos reservatórios de água. Esses recursos classificamse em compensações financeiras e royalties.

A compensação financeira corresponde à indenização paga pela exploração de recursos hídricos para geração de energia elétrica, e, com base nas disposições legais, o montante recolhido das concessionárias e empresas autorizadas a produzir energia elétrica, a título de compensação financeira por uso do recurso hídrico, corresponde a $6,75 \%$ do valor da energia elétrica produzida.

Especificamente, os royalties hidrelétricos correspondem à compensação financeira por uso de recurso hídrico pago por Itaipu Binacional ao Brasil, cuja distribuição obedece à mesma sistemática de distribuição da compensação financeira.

Para os royalties hidrelétricos, de uma parcela de $90 \%$ destinada aos Estados e Municípios, $85 \%$ são distribuídos àqueles diretamente atingidos 
pelo reservatório da usina, enquanto os $15 \%$ restantes são divididos entre os Estados e os Municípios afetados por reservatórios a montante da usina de Itaipu, os quais contribuem para o incremento de energia nela produzida (ANEEL, 2007b).

Em 2007, no estado de Minas Gerais, 138 municípios foram beneficiados por indenizações hidrelétricas, alguns dos quais tiveram alta participação destas indenizações sobre a receita orçamentária municipal total. Nesses casos, parcela significativa das melhorias e dos investimentos públicos estaria relacionada com o recebimento desse tipo de recurso financeiro (ANEEL, 2007b).

Considerando os municípios recebedores de recursos compensatórios hidrelétricos, no estado de Minas Gerais, durante o período de 1993 a 2006, desenvolveu-se a proposta de avaliar a participação e a importância dos recursos compensatórios no financiamento do investimento público e nas principais despesas sociais desses municípios.

Alguns estudos já avaliaram, de forma metodológica diversa, os efeitos encadeados por indenizações compensatórias geradas pela exploração de recursos minerais, os quais, em sua maioria, deram ênfase aos royalties da exploração do petróleo, como os trabalhos de Pacheco (2003), Oliveira (2003), Kupfer (2000) e Nascimento (1999) e outros. Os estudos de caso sobre os efeitos sociais e ambientais provocados pela construção de UHEs não abordaram, especificamente, a relação entre recurso compensatório e gasto público, como o estudo feito pelo Serviço de Apoio a Micro e Pequenas Empresas - SEBRAE (2007), os relatórios primários de Piacenti et al. (2003) e Piacenti e Lima (2002) sobre Itaipu, e o ensaio histórico de Bortoleto (2001).

A importância deste estudo se deve à verificação dos efeitos gerados pelos recursos compensatórios hidrelétricos sobre as despesas municipais, ou seja, a relação entre compensações financeiras e royalties hidrelétricos e financiamento do investimento público municipal e das principais despesas sociais (habitação e urbanismo, saúde e saneamento e educação 
e cultura) dos municípios beneficiados por esses recursos, no estado de Minas Gerais.

\section{Referencial analítico}

\subsection{Indicadores econômico-financeiros e taxas de crescimento}

Neste trabalho, para verificar a participação dos recursos compensatórios hidrelétricos e das principais fontes de arrecadação na receita orçamentária municipal, utilizaram-se os indicadores de proporção, calculados para o período de 1993 a 2006, conforme apresentado a seguir.

$$
\begin{aligned}
& \left(\frac{R O Y}{R O M}\right) ; \\
& \left(\frac{F P M}{R O M}\right) ; \\
& \left(\frac{I C M S}{R O M}\right) ; \\
& \left(\frac{I P T U}{R O M}\right) ; \\
& \left(\frac{I S S}{R O M}\right) ; \\
& \left(\frac{T X M}{R O M}\right) ;
\end{aligned}
$$


em que $R O M$ é a receita orçamentária municipal, e as arrecadações, em cada indicador, são o Recurso Compensatório Hidrelétrico - ROY, o Fundo de Participação Municipal - FPM, o Imposto Sobre Circulação de Mercadorias de Serviços - ICMS, o Imposto Predial Territorial Urbano - IPTU, o Imposto Sobre Serviço de Qualquer Natureza - ISS e as taxas municipais -TXM.

De forma complementar, taxas médias de crescimento foram calculadas para cada despesa analisada (investimento, habitação e urbanismo, saúde e saneamento e educação e cultura) e para cada fonte de receita (recursos compensatórios hidrelétricos, FPM, ICMS, IPTU, ISS e taxas municipais), no período considerado, como segue:

Taxa de crescimento $=\left(\sqrt[n]{V_{f}-V_{i}}-1\right) \cdot 100$,

em que $n$ é o número de anos, no período; $V_{f}$, valor no período final; e $V_{i}$, valor no período inicial, para cada taxa de crescimento calculada.

\subsection{Dados em painel: procedimentos econométricos}

A organização dos dados coletados sobre despesas públicas e sobre principais fontes de arrecadação, para cada município recebedor de recursos compensatórios pagos por UHEs, caracteriza-se pela formação de um painel de dados.

De acordo com Marques (2000), uma especificação simples para um modelo linear, com dados em forma de painel, é a seguinte:

$$
Y_{i j}=\alpha_{i}+\sum_{k=2}^{K-1} \beta_{k} X_{i j}+u_{i j}
$$


em que, $Y_{i j}$ é a variável dependente, nesta análise, despesas municipais selecionadas para avaliação em cada função estimada (investimento, despesa com habitação e urbanismo, despesa com saúde e saneamento e despesa com educação e cultura), e o parâmetro $\beta$ é o coeficiente associado a cada variável explicativa, cujos valores, para i-ésimo indivíduo, no tempo j, são representados por $X_{i j}$. Especificamente, neste estudo, as variáveis explicativas são as principais fontes de receita municipal (Fundo de Participação Municipal - FPM, Imposto Sobre Circulação de Mercadorias e Serviços - ICMS, Imposto Predial Territorial Urbano IPTU, Imposto Sobre Serviço de Qualquer Natureza - ISS e taxas municipais) e os recursos compensatórios hidrelétricos; $u_{i j}$, termo genérico de perturbação, que segue distribuição normal $\left(0 ; \sigma_{u}^{2}\right)$ e apresenta $E\left(u_{i j} \alpha_{i}\right)=0$ e $E\left(u_{i j} X_{i j}\right)=0$. O termo $\alpha_{i}$ representa um termo estocástico próprio dos efeitos individuais, que busca capturar todas as características não observáveis, inerentes a cada município e invariantes ao longo do tempo, tal que $\alpha_{i}$ segue distribuição normal $\left(0 ; \sigma_{\alpha}^{2}\right)$.

Da mesma forma que $\alpha_{i}$ capta os efeitos das unidades seccionais, o modelo pode, também, captar os efeitos específicos no tempo, assumindo, assim, a formulação:

$$
Y_{i j}=\alpha_{i}+\lambda_{j}+\sum_{k=2}^{K-1} \beta_{k} X_{i j}+u_{i j}
$$

em que o termo $\delta_{j}$ é o efeito fixo temporal, representando um termo estocástico próprio dos efeitos temporais, que captura todas as características não observáveis, inerentes aos períodos e invariantes para cada município, tal que $\lambda_{j}$ segue distribuição normal $\left(0, \sigma_{\lambda}^{2}\right)$.

O efeito específico $\alpha_{i}$ pode, ou não, estar correlacionado com as variáveis explicativas $X i j$, sendo que o método de estimação dependerá, 
fundamentalmente, desta hipótese. São dois os modelos mais comuns para estimação com dados em forma de painel. A primeira abordagem, Efeitos Fixos - EF, admite que diferenças entre os indivíduos possam ser captadas por diferentes interceptos, sendo um intercepto para cada município. Nessa formulação, os efeitos específicos podem estar, livremente, correlacionados com as demais variáveis explicativas. Então, na estimação utiliza-se um modelo de regressão múltipla, com variáveis binárias para cada unidade seccional, o que faz com que o intercepto seja específico a cada uma das unidades, captando a heterogeneidade entre elas. O estimador de Mínimos Quadrados Ordinários - MQO seria um estimador consistente e eficiente para o modelo, nesse caso, denominado Mínimos Quadrados com Variável Dummy (MQVD).

Para verificar se o modelo de EF é o melhor, em relação ao modelo com ausência de efeitos, utiliza-se um teste Chow de restrição, em que o modelo restrito é o modelo com ausência de efeitos, enquanto o irrestrito é aquele com presença de efeitos. A rejeição da hipótese nula, segundo a qual os efeitos não existem, implica que o modelo de efeitos fixos seja o mais adequado (PINDYCK e RUBINFELD, 2004).

Quando o modelo escolhido segue a abordagem de Efeitos Aleatórios (EA), admite-se que o efeito específico, não observável, $\alpha_{i}$, seja não correlacionado com as variáveis explicativas, ou seja, $\operatorname{Cov}\left(X_{i}, \alpha_{i}\right)=0$.

\subsection{Modelo estimado ${ }^{4}$}

Neste trabalho, a estimação dos modelos tem, como referência, as finanças públicas e os fatores determinantes da expansão dos gastos do governo. É considerado também o fato de que a limitação da receita do governo constitui o principal fator a explicar a expansão das despesas públicas, conforme defendido por Lotz (1970) e de acordo com as idéias de Peacock e Wiseman (1970).

\footnotetext{
4 Para verificar se o modelo estimado apresenta autocorrelação, utilizou-se o teste de Breusch-Godfrey (BG).
} 
O seguinte modelo foi estimado para cada despesa pública selecionada:

$$
\begin{aligned}
\log \text { DespM }_{i j} & =\alpha_{i}+\log \beta_{2} R O Y_{i j}+\log \beta_{3} F P M_{i j}+\log \beta_{4} I C M S_{i j}+\log \beta_{5} I P T U_{i j}+\log \beta_{6} I S S_{i j}, \\
& +\log \beta_{7} T M S_{i j}+u_{i j}
\end{aligned}
$$

em que $\operatorname{Desp}_{i j}$ é despesa municipal selecionada, do município $i$, no período $j ; R O Y_{i j}$, compensações financeiras e royalties hidrelétricos recebidos pelo município $i$, no período $j ; F P M_{i j}$, FPM recebido pelo município $i$, no período $j$; ICMS $S_{i j}$, cota parte do ICMS recebida pelo município $i$, no período $j$; IPTU $U_{i j}$, IPTU recebido pelo município $i$, no período $j ; I S S_{i j}$, ISS recebido pelo município $i$, no período $j ; T X M_{i j}$, taxas municipais recebidas pelo município $i$, no período $j ; i$, subscrito individual, $i=1, \ldots, 57$; e $j$, subscrito temporal, $j=1993, \ldots, 2006$.

\subsection{Fonte de dados}

Foram considerados, no estudo, os 57 municípios recebedores de recursos compensatórios, no Estado de Minas Gerais, no período de 1993 a 2006 - Abaeté, Além Paraíba, Alfenas, Alterosa, Antônio Dias, Araporã, Areado, Biquinhas, Botelhos, Cabo Verde, Campo Belo, Campo do Meio, Campos Gerais, Canápolis, Candeias, Carrancas, Centralina, Conceição das Alagoas, Conquista, Cristais, Divinópolis, Elói Mendes, Fama, Felixlândia, Formiga, Fronteira, Frutal, Guanhães, Guapé, Guaraciaba, Gurinhatã, Ibiraci, Itapagipe, Ituiutaba, Iturama, Itutinga, Lavras, Leopoldina, Limeira do Oeste, Madre de Deus de Minas, Nepomuceno, Passos, Pimenta, Poços de Caldas, Pompéu, Sacramento, Santa Vitória, Santos Dumont, São Francisco de Sales, São Geraldo do Abaeté, São João Batista do Glória, Três Marias, Tupaciguara, Uberaba, Uberlândia e Varginha.

Foram utilizados os dados disponíveis em publicações da Agência Nacional de Energia Elétrica - ANEEL, do Instituto Brasileiro de Geografia e Estatística - IBGE, do Instituto de Pesquisa e Economia Aplicada IPEA e da Secretaria do Tesouro Nacional -STN. 
Os valores monetários foram deflacionados pelo Índice Geral de Preços Disponibilidade Interna - IGP-DI, da Fundação Getúlio Vargas.

\section{Resultados e discussão}

\subsection{Formação da receita orçamentária municipal}

No período em estudo, os recursos provenientes das compensações financeiras por uso de recurso hídrico - ROY, do Fundo de Participação Municipal - FPM, do Imposto Sobre Circulação de Mercadorias e Serviços - ICMS, do Imposto Predial Territorial Urbano - IPTU, do Imposto Sobre Serviço de Qualquer Natureza e das taxas municipais foram responsáveis, em média, por $70 \%$ da formação da receita orçamentária municipal. A proporção de cada recurso sobre a receita orçamentária, em termos percentuais, é apresentada na Tabela 1.

Devido à baixa densidade populacional, o FPM, cujo valor de repasse foi inversamente proporcional à população, foi o recurso mais expressivo na formação da receita desses municípios, sendo responsável por 33\% da receita orçamentária municipal. De acordo com os índices de proporções calculados, os municípios que se destacaram, com relação à dependência deste recurso, foram Biquinhas (67,51\%), Itutinga $(62,96 \%)$, Madre de Deus de Minas (61,31\%) e Fama (60,79\%).

O ICMS apresentou participação média de $26 \%$, e, para os municípios Antônio Dias, Fronteira, Sacramento e Iturama, foi de 63,64\%, 52,87\%, $45,31 \%$ e $44,18 \%$, respectivamente. Nesses municípios, além do tradicional comércio local, havia concentração da produção agrícola do estado, o que fez com que as relações de negócio e o trânsito de matéria-prima e produto fossem relativamente mais significantes.

As compensações financeiras foram responsáveis, em média, por 4,54\% da formação da receita orçamentária total. Em alguns municípios, como Guapé, São Francisco de Sales, Tupaciguara e Cristais, os recursos compensatórios chegaram a representar cerca de 20\%, 17,24\%, 14,54\% 
e $13,64 \%$, respectivamente. As arrecadações referentes ao IPTU, ISS e taxas municipais foram menos significativas.

\subsection{Evolução das despesas e das arrecadações municipais}

As taxas médias de crescimento dos gastos com Investimento Municipal - INV, Habitação e Urbanismo - HABIT, Saúde e Saneamento - SAD, Educação e Cultura - EDU e da Receita Orçamentária - RO e seus principais componentes ROY, FPM, ICMS, IPTU, ISS e taxas municipais são apresentadas na Tabela 2.

A despesa com saúde e saneamento apresentou o maior crescimento médio anual $(11,36 \%)$, no período analisado, com destaque para os municípios de Fama (27,31\%), Cabo Verde (26,07\%) e Alfenas $(25,09 \%)$.

Os municípios de Conceição das Alagoas (15,69\%) e Fronteira (11,18\%) apresentaram as maiores médias de crescimento na despesa com educação e cultura, cuja média foi de $4,85 \%$. Nesta despesa, o município de Araporã $(10,62 \%)$ foi o único que apresentou redução de gastos. 
Tabela 1 - Participação percentual média da arrecadação municipal sobre a receita orçamentária total (1993 - 2006)

\begin{tabular}{|c|c|c|c|c|c|c|c|c|}
\hline \multirow{2}{*}{ Município } & \multirow{2}{*}{ Habitantes } & \multicolumn{7}{|c|}{ Fonte de arrecadação } \\
\hline & & ROY & IPTU & ICMS & FPM & ISS & Taxas & Outros \\
\hline Abaeté & 22.490 & 3,93 & 1,12 & 18,51 & 36,27 & 1,13 & 3,68 & 35,36 \\
\hline Além Paraíba & 33.387 & 1,54 & 2,50 & 24,09 & 29,20 & 3,71 & 4,06 & 34,89 \\
\hline Alfenas & 65.308 & 4,78 & 5,62 & 22,14 & 22,89 & 2,59 & 4,92 & 37,06 \\
\hline Alterosa & 12.823 & 2,72 & 1,30 & 16,77 & 45,84 & 0,64 & 2,85 & 29,88 \\
\hline Antônio Dias & 9.796 & 7,30 & 0,22 & 22,30 & 38,52 & 11,07 & 1,26 & 19,34 \\
\hline Araporã & 5.227 & 5,39 & 0,30 & 63,64 & 15,12 & 0,91 & 0,52 & 14,11 \\
\hline Areado & 12.075 & 5,40 & 2,01 & 18,46 & 46,62 & 0,70 & 0,93 & 25,89 \\
\hline Biquinhas & 2.769 & 0,15 & 0,55 & 12,69 & 67,51 & 0,23 & 0,92 & 17,95 \\
\hline Botelhos & 15.070 & 1,01 & 2,22 & 24,79 & 37,75 & 0,58 & 3,53 & 30,12 \\
\hline Cabo Verde & 13.255 & 0,42 & 1,26 & 26,27 & 47,43 & 0,55 & 2,54 & 21,54 \\
\hline Campo Belo & 49.285 & 0,58 & 4,00 & 16,18 & 30,15 & 1,92 & 2,85 & 44,33 \\
\hline Campo do Meio & 11.378 & 11,21 & 0,13 & 16,65 & 38,21 & 0,07 & 2,28 & 31,46 \\
\hline Campos Gerais & 25.859 & 6,46 & 1,49 & 21,61 & 37,21 & 0,35 & 2,20 & 30,69 \\
\hline Canápolis & 10.798 & 4,29 & 0,35 & 35,98 & 32,57 & 2,65 & 1,95 & 22,22 \\
\hline Candeias & 14.381 & 0,84 & 1,45 & 19,20 & 52,63 & 0,43 & 1,73 & 23,72 \\
\hline Carrancas & 3.915 & 4,49 & 0,36 & 13,34 & 57,25 & 0,54 & 1,59 & 22,43 \\
\hline Centralina & 10.382 & 1,61 & 0,28 & 20,46 & 49,35 & 1,15 & 2,55 & 24,6 \\
\hline Conceição das Alagoas & 16.656 & 4,57 & 1,07 & 32,92 & 25,65 & 1,53 & 2,80 & 31,46 \\
\hline Conquista & 6.246 & 4,16 & 1,07 & 32,53 & 34,72 & 2,22 & 2,14 & 23,15 \\
\hline Cristais & 9.454 & 13,64 & 0,62 & 18,65 & 35,64 & 0,27 & 0,33 & 30,84 \\
\hline Divinópolis & 183.455 & 0,04 & 3,75 & 23,48 & 17,02 & 6,07 & 6,25 & 43,39 \\
\hline Elói Mendes & 21.496 & 1,63 & 1,47 & 24,86 & 36,25 & 1,74 & 2,46 & 31,58 \\
\hline Fama & 2.332 & 5,21 & 0,44 & 12,81 & 60,79 & 0,11 & 1,00 & 19,64 \\
\hline Felixlândia & 12.571 & 11,89 & 1,28 & 16,91 & 36,57 & 0,59 & 3,30 & 29,45 \\
\hline Formiga & 63.739 & 5,26 & 3,13 & 18,29 & 27,70 & 2,01 & 5,23 & 38,38 \\
\hline Fronteira & 8.853 & 5,02 & 2,00 & 52,87 & 23,70 & 0,59 & 0,77 & 15,04 \\
\hline Frutal & 47.397 & 8,48 & 1,31 & 29,49 & 22,64 & 1,55 & 3,10 & 33,42 \\
\hline Guanhães & 27.633 & 1,30 & 2,69 & 16,71 & 41,31 & 3,31 & 3,62 & 31,06 \\
\hline Guapé & 13.674 & 20,28 & 0,39 & 17,34 & 33,77 & 0,26 & 1,51 & 26,45 \\
\hline Guaraciaba & 10.279 & 2,28 & 0,39 & 15,10 & 57,13 & 0,33 & 1,12 & 23,64 \\
\hline Gurinhatã & 6.848 & 1,66 & 0,56 & 27,65 & 39,39 & 0,37 & 1,14 & 29,22 \\
\hline Ibiraci & 9.473 & 5,35 & 0,26 & 44,39 & 24,24 & 1,66 & 0,74 & 23,36 \\
\hline Itapagipe & 11.630 & 7,12 & 1,62 & 27,56 & 34,08 & 0,74 & 1,97 & 26,9 \\
\hline Ituiutaba & 89.597 & 0,37 & 3,00 & 28,89 & 18,07 & 3,59 & 5,72 & 40,36 \\
\hline Iturama & 28.622 & 3,85 & 1,76 & 44,18 & 17,95 & 1,66 & 2,25 & 28,35 \\
\hline Itutinga & 4.185 & 2,64 & 0,90 & 19,60 & 62,96 & 0,96 & 0,98 & 11,95 \\
\hline Lavras & 78.359 & 0,12 & 6,62 & 24,55 & 21,10 & 2,70 & 3,94 & 40,97 \\
\hline Leopoldina & 49.212 & 0,39 & 2,60 & 21,75 & 33,22 & 3,11 & 4,96 & 33,96 \\
\hline Limeira do Oeste & 6.198 & 5,55 & 0,81 & 38,37 & 30,55 & 1,09 & 1,09 & 22,54 \\
\hline Madre de Deus de Minas & 4.597 & 5,10 & 0,21 & 15,55 & 61,31 & 0,18 & 1,03 & 16,62 \\
\hline Muriaé & 91.503 & 0,15 & 2,71 & 18,34 & 29,13 & 4,02 & 4,17 & 41,49 \\
\hline Nepomuceno & 25.102 & 2,10 & 1,18 & 23,53 & 39,88 & 0,58 & 4,18 & 28,56 \\
\hline Passos & 97.519 & 0,92 & 4,81 & 25,84 & 21,82 & 2,48 & 4,79 & 39,33 \\
\hline Pimenta & 7.859 & 6,66 & 1,21 & 16,95 & 37,46 & 0,37 & 3,33 & 34,03 \\
\hline Poços de Caldas & 132.935 & 0,15 & 5,97 & 32,61 & 9,45 & 5,17 & 1,68 & 44,96 \\
\hline Pompéu & 25.538 & 4,14 & 1,54 & 21,37 & 34,86 & 1,18 & 2,63 & 34,27 \\
\hline Sacramento & 21.261 & 10,45 & 1,40 & 45,31 & 18,91 & 1,30 & 1,39 & 21,24 \\
\hline Santa Vitória & 16.501 & 11,86 & 0,79 & 5,20 & 16,87 & 0,85 & 0,85 & 63,58 \\
\hline
\end{tabular}


REVISTA DE ECONOMIA E AGRONEGÓCIO, VOL.8, $N^{o} 1$

\begin{tabular}{lllllllll} 
Santa Vitória & 16.501 & 11,86 & 0,79 & 5,20 & 16,87 & 0,85 & 0,85 & 63,58 \\
Santos Dumont & 46.756 & 0,26 & 4,19 & 28,31 & 36,24 & 3,90 & 4,62 & 22,48 \\
São Francisco de Sales & 5.289 & 17,24 & 0,99 & 28,82 & 28,20 & 0,35 & 1,70 & 22,69 \\
São Gonçalo do Abaeté & 6.071 & 1,84 & 0,44 & 24,19 & 46,79 & 0,45 & 0,78 & 25,52 \\
São João Batista do Glória & 5.926 & 3,24 & 0,26 & 41,68 & 23,03 & 0,51 & 1,64 & 29,64 \\
Três Marias & 24.378 & 6,56 & 1,72 & 39,95 & 26,39 & 3,76 & 2,55 & 19,07 \\
Tupaciguara & 22.306 & 14,54 & 1,78 & 27,66 & 21,71 & 1,49 & 2,46 & 30,37 \\
Uberaba & 249.110 & 0,22 & 3,98 & 35,33 & 11,52 & 5,14 & 4,35 & 39,45 \\
Uberlândia & 492.611 & 0,09 & 3,05 & 39,08 & 5,04 & 8,19 & 3,53 & 41,03 \\
Varginha & 108.170 & 0,13 & 4,91 & 32,78 & 12,47 & 5,73 & 2,50 & 41,49 \\
Média & 42.273 & 4,54 & 1,82 & 26,04 & 33,33 & 1,95 & 2,54 & 29,76 \\
\hline
\end{tabular}

Fonte: Resultados da pesquisa.

No que se refere às principais despesas infraestruturais, os gastos com investimento, com média de 4,04\%, apresentaram valores maiores nos municípios de Santos Dumont (23,80\%) e Botelhos (18,38\%), enquanto São Gonçalo do Abaté $(11,28 \%)$ e Varginha $(9,87 \%)$ apresentaram médias negativas. A despesa com habitação e urbanismo teve média igual a 3,01\%; os municípios de Centralina (23,77\%) e Itutinga (17,78\%) tiveram as maiores taxas de crescimento, enquanto as maiores quedas foram observadas em Felixlândia (13,40\%) e Araporã $(22,72 \%)$, que também apresentou uma das maiores quedas nos gastos com educação e cultura.

Ressalta-se que apenas o município de Araporã apresentou taxa de crescimento negativa nos gastos com educação e cultura, e as despesas com saúde e saneamento apresentaram duas taxas médias negativas em São Gonçalo do Abaeté $(7,55 \%)$ e em Tupaciguara $(7,31 \%)$.

A expansão da receita orçamentária apresentou crescimento médio de $5,47 \%$, e as principais fontes, o ISS $(25,06 \%)$ e o IPTU $(13,64 \%)$, que são recursos arrecadados pelos próprios municípios, e a descentralização, promovida pela Constituição Federal, deram maior autonomia municipal sobre a taxação desses impostos.

O saldo positivo, apresentado em todos os itens de receita, refletiu o aumento da renda disponível da população, no período analisado. Parte do aumento dessa renda disponível foi devida, também, às vantagens locais, ou seja, externalidades provocadas pelo crescimento dos gastos públicos nas despesas sociais e infraestruturais. Dadas as categorias 
sobre as quais incidem os impostos considerados (ICMS, ISS, IPTU e taxas municipais), os efeitos provocados pelos gastos públicos foram, principalmente, a expansão produtiva de bens e serviços e a valorização dos imóveis.

\subsection{Determinantes da expansão dos gastos públicos municipais}

$\mathrm{Na}$ análise dos determinantes da expansão dos gastos públicos, a opção pela abordagem de dados em painel com presença de efeitos fixos - EF, em detrimento da alternativa com presença de efeitos aleatórios - EA, além de se basear nas indicações dadas pelas estatísticas dos testes Chow e Hausman, justifica-se pela melhor adequação à natureza dos dados e aos objetivos macroeconômicos definidos.

A presença de autocorrelação e hererocedasticidade foi verificada por meio dos testes de Breusch-Godfrey e Durbin-Watson e do teste de Bartlett, respectivamente, e apenas a autocorrelação de primeiro grau (AR 1) foi detectada e corrigida pela ponderação dos coeficientes pelo termo correlacionado, em cada uma das funções. 
Tabela 2 - Expansão média das despesas e receitas municipais (1993

\begin{tabular}{|c|c|c|c|c|c|c|c|c|c|c|c|}
\hline Município & INV & SAD & EDU & HABIT & RO & FPM & ICMS & ROY & IPTU & ISS & Taxas \\
\hline Abaeté & 5,85 & 12,99 & 7,66 & $-7,27$ & 5,51 & 6,13 & 6,40 & 4,18 & 14,01 & 17,56 & $-3,01$ \\
\hline Além Paraíba & 8,60 & 7,50 & 6,05 & 9,85 & 6,18 & 3,47 & 7,20 & 5,24 & 12,93 & 14,87 & 8,99 \\
\hline Alfenas & $-1,94$ & 25,09 & 9,33 & 6,04 & 9,77 & 4,11 & 5,58 & $-0,72$ & 24,48 & 19,33 & 3,88 \\
\hline Alterosa & 1,17 & 13,99 & 5,39 & 5,15 & 5,10 & 3,57 & 10,90 & $-0,26$ & 20,76 & 15,11 & 4,62 \\
\hline Antônio Dias & $-0,01$ & 7,82 & 4,69 & 4,00 & 8,38 & 3,59 & 16,23 & 8,49 & 10,96 & 23,85 & $-7,79$ \\
\hline Araporã & 0,45 & 0,86 & $-10,62$ & $-22,72$ & 11,28 & 4,03 & 15,67 & 5,23 & 13,19 & 31,37 & $-4,55$ \\
\hline Areado & $-1,88$ & 11,65 & 7,34 & $-1,32$ & 2,81 & 1,59 & 8,20 & 0,09 & 15,25 & 35,05 & 7,75 \\
\hline Biquinhas & 4,72 & 12,72 & 3,51 & $-7,22$ & 5,62 & 3,46 & 16,49 & 9,37 & $-1,87$ & 8,13 & $-2,28$ \\
\hline Botelhos & 18,38 & 10,59 & 6,51 & 10,47 & 5,28 & 3,48 & 5,71 & 2,92 & 27,82 & 42,55 & $-3,48$ \\
\hline Cabo Verde & $-1,77$ & 26,07 & 1,43 & 1,58 & 3,57 & 3,91 & 5,49 & $-8,10$ & 6,57 & 42,25 & 0,24 \\
\hline Campo Belo & 4,90 & 17,85 & 5,35 & 2,04 & 4,12 & 3,88 & 3,96 & $-4,53$ & 16,41 & 9,85 & $-2,17$ \\
\hline Campo do Meio & 11,36 & 3,81 & 1,81 & 1,45 & 3,22 & 6,01 & 1,97 & $-2,31$ & 20,48 & 48,75 & $-1,59$ \\
\hline Campos Gerais & 1,50 & 11,86 & 3,26 & 1,20 & 4,81 & 3,31 & 5,26 & $-1,14$ & 12,86 & 13,57 & $-3,93$ \\
\hline Canápolis & 3,70 & 16,02 & 3,92 & 2,76 & 6,38 & 0,98 & 6,88 & 7,76 & 11,30 & 54,24 & $-2,90$ \\
\hline Candeias & 5,94 & 11,96 & 2,94 & 4,95 & 5,03 & 2,09 & 6,65 & $-5,00$ & 27,99 & 26,59 & 11,59 \\
\hline Carrancas & 7,78 & 8,59 & 6,03 & 10,68 & 4,38 & 3,47 & 7,81 & 8,77 & 30,29 & 44,03 & 10,09 \\
\hline Centralina & $-5,29$ & 19,64 & 2,19 & 23,77 & 3,99 & 2,58 & 6,01 & 10,90 & 10,12 & 28,71 & $-10,04$ \\
\hline Conceição das Alagoas & 12,26 & 12,77 & 15,69 & 6,62 & 7,62 & 5,24 & 10,58 & 3,93 & 14,06 & 27,49 & $-2,64$ \\
\hline Conquista & 7,51 & 11,47 & 3,36 & 2,68 & 6,19 & 3,47 & 9,96 & 39,83 & 11,93 & 7,51 & $-5,80$ \\
\hline Cristais & $-2,47$ & 5,47 & 5,82 & 8,92 & 3,13 & 7,08 & 8,89 & $-0,25$ & 2,83 & 19,99 & 5,60 \\
\hline Divinópolis & 6,15 & 13,31 & 4,55 & 5,76 & 7,77 & 2,99 & 2,85 & $-1,83$ & 15,62 & 6,97 & 2,33 \\
\hline Elói Mendes & 10,36 & 13,83 & 6,69 & 6,22 & 5,33 & 7,32 & 2,62 & $-0,64$ & 24,27 & 48,46 & $-4,49$ \\
\hline Fama & $-7,31$ & 27,31 & 2,83 & $-5,54$ & 3,68 & 3,44 & 9,34 & 0,54 & $-3,62$ & 39,81 & 8,54 \\
\hline Felixlândia & 0,40 & 3,27 & 6,98 & $-13,40$ & 5,72 & 3,48 & 7,68 & 4,12 & $-2,06$ & 31,60 & $-2,82$ \\
\hline Formiga & 3,00 & 19,15 & 3,44 & 2,53 & 3,97 & 2,62 & 2,13 & $-0,88$ & 9,49 & 10,64 & $-0,14$ \\
\hline Fronteira & 11,09 & 15,21 & 11,18 & 10,92 & 11,56 & 3,34 & 20,24 & 2,96 & 18,30 & 61,44 & 21,18 \\
\hline Frutal & 0,54 & 10,07 & 5,85 & $-4,55$ & 3,15 & 3,52 & 1,53 & 1,40 & 18,40 & 10,06 & 1,59 \\
\hline Guanhães & 4,96 & 17,27 & 3,49 & 0,50 & 8,13 & 3,42 & 5,89 & $-0,30$ & 11,66 & $-0,35$ & 5,87 \\
\hline Guapé & 3,83 & 11,09 & 2,65 & 2,58 & 2,88 & 3,57 & 2,13 & $-1,28$ & 9,08 & 22,04 & $-2,62$ \\
\hline Guaraciaba & 10,98 & 15,65 & 6,95 & 7,40 & 6,42 & 1,42 & 16,11 & 3,04 & 7,92 & 17,38 & $-0,66$ \\
\hline Gurinhatã & 17,14 & 5,20 & 2,45 & 9,59 & 4,95 & 3,59 & 5,82 & 3,17 & 1,10 & 36,10 & 0,35 \\
\hline Ibiraci & 5,04 & 9,85 & 6,81 & 12,39 & 4,55 & 5,62 & 12,03 & 1,37 & $-3,82$ & 36,80 & $-6,10$ \\
\hline Itapagipe & 2,47 & 7,42 & 4,64 & 5,97 & 4,19 & 1,86 & 5,12 & 3,06 & 28,18 & 44,19 & 13,95 \\
\hline Ituiutaba & 3,80 & 13,70 & 4,84 & 0,67 & 6,48 & 2,73 & 4,37 & 3,67 & 19,41 & 9,04 & 4,36 \\
\hline Iturama & $-2,51$ & 10,99 & 6,82 & 1,15 & 3,99 & 1,07 & 5,72 & 1,99 & 17,47 & 13,79 & $-0,68$ \\
\hline Itutinga & 9,52 & 4,85 & 4,91 & 17,78 & 5,46 & 3,44 & 11,63 & 4,38 & $-6,09$ & 53,52 & 4,29 \\
\hline Lavras & 5,15 & 15,86 & 7,86 & $-0,82$ & 6,23 & 4,07 & 0,57 & 6,81 & 20,02 & 20,68 & $-0,59$ \\
\hline Leopoldina & 1,10 & 8,72 & 5,62 & 2,93 & 3,69 & 4,81 & 0,60 & 4,74 & 14,93 & 4,68 & 7,87 \\
\hline Limeira do Oeste & 7,92 & 11,14 & 8,33 & 7,72 & 8,07 & 3,47 & 20,14 & 7,73 & 6,86 & 23,70 & 0,33 \\
\hline Madre de Deus de Minas & 6,20 & 17,51 & 4,28 & $-1,38$ & 5,61 & 3,46 & 10,72 & $-2,88$ & 13,06 & 51,52 & 11,70 \\
\hline Muriaé & 11,62 & 17,16 & 7,24 & 2,33 & 9,39 & 4,22 & 3,14 & 7,05 & 21,51 & 11,33 & 13,48 \\
\hline Nepomuceno & $-1,15$ & 5,79 & 3,69 & 3,35 & 3,93 & 3,46 & 4,15 & 0,89 & 13,48 & 43,26 & 6,77 \\
\hline Passos & 7,13 & 10,83 & 4,20 & 7,62 & 4,67 & 3,98 & 1,25 & $-2,17$ & 22,67 & 12,38 & $-8,50$ \\
\hline Pimenta & 7,77 & 13,99 & 4,88 & 4,86 & 6,89 & 3,46 & 9,28 & $-1,38$ & 14,24 & 28,34 & $-4,00$ \\
\hline Poços de Caldas & 13,86 & 13,09 & 5,39 & $-7,60$ & 9,52 & 7,38 & 1,65 & 6,92 & 13,25 & 10,84 & 20,94 \\
\hline Pompéu & $-7,45$ & 3,36 & 6,65 & 2,46 & 5,17 & 4,62 & 6,42 & 3,79 & 6,71 & 11,40 & 9,84 \\
\hline Sacramento & $-1,58$ & 16,80 & 3,82 & $-4,97$ & 4,92 & 2,23 & 5,35 & 6,04 & 19,45 & 27,89 & $-3,97$ \\
\hline Santa Vitória & $-1,23$ & 7,75 & 1,80 & $-2,57$ & 3,81 & 1,96 & 35,57 & 3,13 & 5,82 & 8,34 & 23,21 \\
\hline Santos Dumont & 23,80 & 13,52 & 4,87 & 3,11 & 7,28 & 4,05 & 6,60 & 3,45 & 29,99 & 11,09 & 13,14 \\
\hline São Francisco de Sales & 0,90 & 8,79 & 1,11 & 5,80 & 1,07 & 6,58 & $-3,25$ & 1,01 & 19,18 & 58,49 & 10,85 \\
\hline São Gonçalo do Abaeté & $-11,28$ & $-7,55$ & 4,23 & 8,38 & $-1,77$ & 0,44 & 4,65 & 3,04 & 11,90 & 27,86 & $-19,60$ \\
\hline São João Batista do Glória & 9,75 & 10,96 & 8,48 & 16,26 & 7,63 & 3,52 & 18,69 & 5,28 & 7,98 & 44,65 & 2,92 \\
\hline Três Marias & $-1,28$ & 11,89 & 5,40 & $-4,34$ & 6,35 & 2,96 & 4,69 & 4,20 & 6,59 & 15,07 & $-7,92$ \\
\hline Tupaciguara & $-1,48$ & $-7,31$ & 1,59 & $-5,63$ & 2,11 & 1,50 & $-2,30$ & 2,59 & 13,65 & 13,03 & 3,23 \\
\hline Uberaba & 11,90 & 10,66 & 4,97 & 4,58 & 8,05 & 3,34 & 3,49 & 4,61 & 15,91 & 10,09 & 19,90 \\
\hline Uberlândia & $-1,49$ & 7,54 & 3,86 & 5,16 & 4,86 & 3,34 & $-0,02$ & 26,46 & 14,86 & 9,60 & 6,93 \\
\hline Varginha & $-9,87$ & 10,09 & 1,40 & 0,66 & 3,62 & 4,42 & $-1,58$ & 1,48 & 17,73 & 12,04 & 1,61 \\
\hline Média & 4,04 & 11,36 & 4,85 & 3,01 & 5,47 & 3,62 & 7,21 & 3,54 & 13,64 & 25,06 & 2,73 \\
\hline
\end{tabular}

Fonte: Resultados da pesquisa. 


\subsection{Investimento público}

Com exceção das taxas municipais, as demais variáveis foram estatisticamente significativas a 5\% de probabilidade (Tabela 3 ).

O FPM foi a variável à qual o investimento público mostrou-se mais sensível, ou seja, o valor igual a 0,42 indicou que aumentos na ordem de $10 \%$ no repasse do FPM levaram o investimento público a aumentar $4,2 \%$, aproximadamente, o que faz jus à dependência da receita orçamentária dos municípios analisados ao repasse deste recurso, revelada pelas proporções calculadas anteriormente.

Conforme hipótese do trabalho, os recursos compensatórios - ROY mostraram grande importância na determinação do investimento público, já que um aumento de $10 \%$ em seu repasse elevaria os investimentos municipais em 2,0\%. Nos municípios analisados, os gastos com investimento público foram determinados, praticamente, pelo FPM e pelos ROY, sendo complementados pelo ISS.

A variável tendência dá indicações do comportamento decrescente da expansão do investimento público, ou seja, mostra a tendência da redução na participação do governo na expansão da infraestrutura municipal, o que pode ser reflexo da transferência, para a iniciativa privada, desta responsabilidade governamental, própria da política neoliberal implementada no período. 
Tabela 3 - Função investimento público municipal, estimada pela presença de efeitos fixos

\begin{tabular}{|c|c|c|c|}
\hline Variáveis & Coeficientes & Erros-padrão & P-valor \\
\hline FPM & $0,471925 * * *$ & 0,119554 & 0,0001 \\
\hline ICMS & $0,134507 * * *$ & 0,082954 & 0,1054 \\
\hline ROY & $0,207500 * * *$ & 0,051310 & 0,0001 \\
\hline IPTU & $0,000281^{\mathrm{NS}}$ & 0,053190 & 0,9958 \\
\hline Taxas & $0,037386^{\mathrm{NS}}$ & 0,037908 & 0,3244 \\
\hline ISS & $0,098636 * * *$ & 0,036157 & 0,0093 \\
\hline Tendência & $-0,025886 * * *$ & $-5,703496$ & 0,0000 \\
\hline $\mathrm{R}^{2}$ & 0,81 & & \\
\hline Estatística F & $44,57 * * *$ & & 0,0000 \\
\hline Durbin-Watson & 2,01 & & \\
\hline BG & 4,44 & & \\
\hline Bartlett & $188,86^{\mathrm{NS}}$ & & 1,0000 \\
\hline Chow & $2,73 * * *$ & & \\
\hline Hausman & $49,71 * * *$ & & 0,0000 \\
\hline
\end{tabular}

Fonte: Resultados da pesquisa.

***significativo a 1\%; **significativo a 5\%; *significativo a 10\%; NS não-significativo.

\subsection{Despesa com saúde e saneamento}

As fontes financiadoras mais expressivas para determinação das despesas com saúde e saneamento foram o FPM, o ICMS, o ISS e os ROY, consecutivamente ( Tabela 4).

A alta significância estatística e as elasticidades iguais a 0,32 e 0,25 para o FPM e para o ICMS, respectivamente, refletem a dependência desta despesa para com os recursos federais e estaduais, repassados aos municípios. No início da década de 90, o governo federal unificou e municipalizou os gastos com saúde, porém, dada a complexidade e dado o alto custo desta conta, repasses vinculados, atualmente proporcionais à população, foram determinantes para o financiamento desta conta. 
O ISS, arrecadação municipal que apresentou maior crescimento no período analisado, obteve elasticidade igual a 0,15 , o que indica que, se sua arrecadação aumentasse em $10 \%$, os aumentos correspondentes à despesa com saúde e saneamento seriam da ordem de 1,5\%.

Apesar da baixa elasticidade, a regressão estimada, mais uma vez, confirma a importância dos recursos compensatórios sobre a expansão dos gastos municipais com saúde e saneamento. No contexto da municipalização desses gastos, esse recurso "extra", proveniente da construção de hidrelétricas para geração de energia, mostra-se importante na complementação do financiamento dessa despesa social, fundamental para internalização e promoção do desenvolvimento e crescimento local.

Com relação ao comportamento ao longo do tempo, a variável tendência mostrou que os gastos com saúde e saneamento foi crescente, revelando a participação, cada vez mais efetiva, das receitas do governo no financiamento da saúde básica. Além de ser uma das atribuições do governo, a assistência à saúde e ao saneamento básico é um gasto que não atrai a iniciativa privada, por envolver custos altos e baixos retornos, em comparação com outros investimentos.

\subsection{Despesa com educação e cultura}

Os gastos municipais com educação e cultura foram muito sensíveis, com relação ao ICMS e ao FPM (Tabela 5). Com base nas elasticidades obtidas, aumentos da ordem de $10 \%$ nos valores desses recursos afetaram os gastos com educação e cultura em $2,27 \%$ e $1,04 \%$, respectivamente. Vale ressaltar que apenas a educação básica é de responsabilidade da administração pública municipal, e, salvo as participações da iniciativa privada, a maior parte dos recursos aplicados nesta despesa é estadual e federal. 
Tabela 4 - Função despesa municipal com saúde e saneamento, estimada com presença de efeitos fixos

\begin{tabular}{cccc}
\hline Variáveis & Coeficientes & Erros-padrão & P-valor \\
\hline FPM & $0,323278 * * *$ & 0,107770 & 0,0028 \\
ICMS & $0,255355^{*}$ & 0,084294 & 0,0025 \\
ROY & $0,014843 *$ & 0,050721 & 0,0699 \\
IPTU & $0,039882^{\text {NS }}$ & 0,053544 & 0,4566 \\
Taxas & $-0,067510^{\mathrm{NS}}$ & 0,036834 & 0,1673 \\
ISS & $0,149367 * * *$ & 0,032485 & 0,0000 \\
Tendência & $0,049471 * * *$ & 0,003902 & 0,0000 \\
R & & & \\
R & 0,867834 & & 0,0000 \\
Estatística F & $69,36 * * *$ & & \\
Durbin-Watson & 2,09 & & 1,0000 \\
BG & 2,96 & & 0,0000 \\
Bartlett & $145,78^{\mathrm{NS}}$ & & \\
Chow & $1,26^{*}$ & & \\
Hausman & $66,52 * * *$ & & \\
\hline
\end{tabular}

Fonte: Resultados da pesquisa. ***significativo a $1 \%$; **significativo a $5 \%$; *significativo a 10\%; NS não-significativo.

O IPTU, as taxas municipais e o ISS também foram importantes para determinação da expansão dos gastos com educação e cultura, cujos efeitos ficaram na ordem de 0,06, 0,09 e 0,04, respectivamente. Essa conta foi a mais sensível a recursos sob a autonomia, estritamente, municipal.

Entretanto, as compensações financeiras e os royalties não foram significativos para expansão das despesas com educação e cultura. Tendo em vista o caráter essencial desta despesa e a ocorrência de repasses vinculados por parte das esferas federal e estadual, é razoável que os recursos compensatórios sejam melhor aproveitados em gastos cujo financiamento não tenham contrapartida garantida, o que reforça o caráter "extra" dessas compensações. 
Tabela 5 - Função despesa municipal com educação e cultura, estimada com presença de efeitos fixos

\begin{tabular}{cccc}
\hline Variáveis & Coeficientes & Erros-padrão & P-valor \\
\hline FPM & $0,103826 *$ & 0,056894 & 0,0685 \\
ICMS & $0,226540 * * *$ & 0,038048 & 0,0000 \\
ROY & $-0,038306^{\mathrm{NS}}$ & 0,023869 & 0,1090 \\
IPTU & $0,062152 * *$ & 0,024535 & 0,0115 \\
Taxas & $0,090317 * * *$ & 0,017631 & 0,0000 \\
ISS & $0,039526 * *$ & 0,016665 & 0,0180 \\
Tendência & $0,005998^{* * *}$ & 0,002064 & 0,0038 \\
& & & \\
R $^{2}$ & 0,94 & & 0,0000 \\
Estatística F & $165,36 * * *$ & & \\
Durbin-Watson & 2,00 & & \\
BG & 1,48 & & 0,0000 \\
Bartlett & 270,78 NS & & \\
Chow & $3,57 * * *$ & & \\
Hausman & $28,00 * * *$ & & \\
\hline
\end{tabular}

Fonte: Resultados da pesquisa.

***significativo a $1 \%$; **significativo a $5 \%$; *significativo a $10 \%$; NS nãosignificativo.

\subsection{Despesa com habitação e urbanismo}

Dentre as variáveis explicativas consideradas na determinação da expansão dos gastos municipais com habitação e urbanismo, as mais significativas foram FPM, taxas municipais, recursos compensatórios, ISS e tendência (Tabela 6).

O FPM, principal fonte formadora da receita orçamentária dos municípios considerados, apresentou elasticidade igual a $19 \%$. Os recursos provenientes do ISS e das taxas municipais também foram importantes para determinação desta despesa, com elasticidades iguais a 0,07 e 0,09, respectivamente. 
Os recursos compensatórios apresentaram elasticidade igual a 0,10 , constituindo o segundo recurso mais importante para esta despesa, o que permite afirmar que tiveram grande importância em despesas infraestuturais.

O gasto governamental com habitação e urbanismo também vem sendo transferido, gradualmente, para a iniciativa privada ou financiado por meio das facilidades possibilitadas pelo Governo Federal, por meio do financiamento da casa própria.

Tabela 6 - Função despesa com habitação e urbanismo, estimada com presença de efeitos fixos

\begin{tabular}{cccc}
\hline Variáveis & Coeficientes & Erros-padrão & P-valor \\
\hline FPM & $0,192140 *$ & 0,103540 & 0,0639 \\
ICMS & $0,058603^{\mathrm{NS}}$ & 0,082535 & 0,4779 \\
ROY & $0,100907 * *$ & 0,048502 & 0,0379 \\
IPTU & $-0,004648^{\mathrm{NS}}$ & 0,050978 & 0,4274 \\
Taxas & $0,067059^{*}$ & 0,036321 & 0,0653 \\
ISS & $0,099460 * * *$ & 0,035450 & 0,0052 \\
Tendência & $-0,014429 * * *$ & 0,004712 & 0,0032 \\
& & & \\
R $^{2}$ & 0,84 & & 0,0000 \\
Estatística F & $56,27 * * *$ & & \\
Durbin-Watson & 1,89 & & 1,0000 \\
BG & 7,4 & & 0,0000 \\
Bartlett & 226,56 & & \\
Chow & $1,39 * *$ & & \\
Hausman & $66,52 * * *$ & & \\
\hline
\end{tabular}

Fonte: Resultados da pesquisa.

***significativo a $1 \%$; **significativo a $5 \%$; *significativo a $10 \%$; NS nãosignificativo. 


\section{Conclusões}

Os resultados obtidos permitiram inferir que a expansão dos gastos públicos, nos municípios recebedores de compensações financeiras por uso de recursos hídricos, em Minas Gerais, foi fortemente determinada pela receita orçamentária disponível.

Nos municípios selecionados, concentrados basicamente nas regiões do Triângulo Mineiro, Alto Paranaíba, Central e Sul, o FPM, o ICMS, os recursos compensatórios hidrelétricos, o IPTU, o ISS e as taxas municipais foram principais fontes de arrecadação, visto que chegam a representar, em média, $70 \%$ da composição da receita orçamentária municipal.

As arrecadações que apresentaram maiores percentuais de crescimentos foram o ISS $(25,06 \%)$ e o IPTU $(13,64 \%)$, seguidos do ICMS $(7,21 \%)$, do FPM $(3,62 \%)$, das compensações hidrelétricas $(3,54 \%)$ e das taxas municipais $(2,73 \%)$.

No que se refere ao crescimento dos gastos públicos, a despesa com saúde e saneamento $(11,36 \%)$ apresentou o maior percentual médio de crescimento, seguida pela despesa com educação e cultura $(4,85 \%)$, o que se justifica pelo aumento na disponibilidade dos recursos vinculados e dos principais recursos determinantes da expansão das despesas FPM e ICMS. As elasticidades obtidas para esses itens, na estimação da função referente a gastos com educação e cultura, foram 0,10 e 0,22 , respectivamente. Esta foi a única despesa que não apresentou elasticidade estatisticamente significativa para a variável explicativa recursos compensatórios hidrelétricos, devido à existência de repasses específicos.

Para a despesa com saúde e saneamento, as únicas variáveis explicativas não-significativas foram o IPTU e as taxas municipais. Apesar de apresentarem baixa elasticidade $(0,14)$, os recursos compensatórios foram importantes para a despesa com saúde e saneamento, o que se deve às obras estruturais de saneamento custeadas nessa conta. 
O investimento $(0,40)$ e a despesa com habitação e urbanismo $(0,03)$ apareceram em terceiro e quarto lugar, respectivamente. A expansão de ambas as despesas apresentou maior sensibilidade aos recursos compensatórios hidrelétricos e ao FPM.

Dadas a significância e a magnitude das elasticidades estimadas para as compensações hidrelétricas, em cada despesa analisada ressalta-se a importância deste recurso para o financiamento de obras infraestruturais, principalmente as de financiamento regular não vinculado.

Nesse contexto, a expansão das arrecadações é devida não apenas à descentralização da arrecadação municipal intensificada pela Constituição Federal de 1988, mas também às externalidades provocadas pela expansão do investimento público e das despesas sociais analisadas. A criação de vantagens locacionais de infraestrutura e de fatores produtivos promoveu aumentos na renda, que, provavelmente, retornaram para a administração municipal em forma de arrecadação.

\section{Referências}

ANEEL - Agência Nacional de Energia Elétrica. Banco de informações de geração. Disponível em: http://www.aneel.gov.br/aplicacoes/ capacidadebrasil. asp.Acesso em: 10 abr., 2007.

. Compensação financeira. Disponível em: http:// www.aneel.gov.br Acesso em: 10 abr. 2007.

A compensação financeira e o seu município. Brasília: ANEEL, 2007.

BORTOLETO, E. M. A implantação de grandes hidrelétricas: desenvolvimento, discurso e impactos. Geografares. Vitória, n. 2, p. $53-$ 62, Jun., 2001. 
KUPFER, D. Impacto econômico da expansão da indústria do petróleo. Relatório final. Grupo indústria e competitividade - Instituto de Economia/ UFRJ, 2000. Disponível em: <http://www.ie.ufrj.br/gic/ pdfs/2000-1_Kupfer_et_al.pdf>. Acesso em 15 Nov., 2007.

LOTZ, J. Patterns of government spending in developing countries. The Manchester school of economics ando social studies. Manchester, Inglaterra, v.38, n. 2, p.119-144, Jun., 1970.

MUSGRAVE, R. A.; MUSGRAVE, P. B. Finanças públicas. Rio de Janeiro: Editora Campus, 1980.

OLIVEIRA, L. A Importância dos royalties de petróleo e da participação especial para as finanças do estado do Rio de Janeiro e municípios fluminenses. Conjuntura e informação, Rio de Janeiro, n. 21, p. 3-5, fev./abr., 2003.

PACHECO, C. A. G. A aplicação e o impacto dos royalties do petróleo dos municípios confrontantes da Bacia de Campos. Rio de Janeiro, RJ: IE/ UFRJ, 2003. 139p. Monografia (Bacharelado em Ciências Econômicas) Universidade Federal do Rio de Janeiro, 2003.

PEACOCK, A. T.; WISEMAN, J. The growth of public expenditure in United Kingdom. Princeton: Princeton University Press, 1970.

PIACENTI, C. A.; LIMA, J. F. Análise do impacto dos reservatórios das hidroelétricas no desenvolvimento econômico microrregional. Toledo, PR: Fundação Araucária/ Curso de Ciências Econômicas/ UNIOESTE. Projeto 612. Projeto concluído. 2002.

PIACENTI, C. A et al. Apontamentos sobre a economia dos municípios atingidos pelas hidrelétricas de Salto Caxias e Itaipu Binacional. Revista paranaense de desenvolvimento. Curitiba, n. 104, p. 103- 123, Jan./ Jun. 2003.

PINDYCK, R. S.; RUBINFELD, D. L. Econometria: modelos e previsões. $4^{\text {a }}$ ed. Rio de Janeiro: Elsevier, 2004. 
REZENDE, F. Finanças públicas. $2^{\mathrm{a}}$ ed. São Paulo: Editora Atlas, 2001.

SEBRAE - Serviço Brasileiro de Apoio às Micro e Pequenas Empresas. Utilização de royalties e compensações financeiras da exploração da energia hidroelétrica na promoção do desenvolvimento local. Disponível em:<http://www.dce.sebrae.com.br/bte/bte.nsf/ 0A70ADD36FF55C4D032570660044F4E4/\$File/NT000AAD9E.pdf > Acesso em: 20 Jun. 2007.

\begin{abstract}
Based on the regulation about the compensatory payment for using the water resources and land flooding for the generation of electric power, this study was carried out to evaluate the effect of the "extra" financial resource - financial compensations and hydroelectric royalties - in budget revenue formation and in the public expenses determination of the receiving municipalities in Minas Gerais. From the discussions about the determinants of the government expenses the public county accounts were estimated regressions with data panel for each of the municipal expenses under consideration (investment, housing and urbanization, health and sanitation, education and culture), and proportion indexes and growth rates of expenses and incomes were calculated. The main sources of municipal income (compensatory resources, Municipal Participation Fund - FPM, Taxes on Circulation of Goods and Services - ICMS, Urban Territorial Property Tax - IPTU, Any nature Service Tax - ISS, and county taxes) served as explanatory variables. The results showed the budget revenue availability is significant to determining the county public expenses, and confirmed the power of the financial payoffs and hydroelectric royalties on expansion of the county expense in local infrastructure. This was apprehended mainly by the elasticities of the functions estimated for the investment, housing, urbanization, health and sanitation expenses.
\end{abstract}

Keywords: Hydroelectric royalties, budget revenue, public expenses. 